\title{
Changes in Alveolar Bone Width Following Bone Expansion
}

\author{
Meltem Koray $^{1 *}$, Neslihan Senel2 ${ }^{2}$, Aysegul Senemtası1 ${ }^{1}$, lknur Özcan², Mehmet Yaltırık \\ ${ }^{1}$ Istanbul University, Faculty of Dentistry, Department of Oral and Maxillofacial Surgery, İstanbul, Turkey \\ ${ }^{2}$ Istanbul University, Faculty of Dentistry, Department of Oral and Maxillofacial Radiology, İstanbul, Turkey \\ Email: *mkoray@istanbul.edu.tr
}

How to cite this paper: Koray, M., Senel, N., Senemtası, A., Özcan, I. and Yaltırık, M. (2017) Changes in Alveolar Bone Width Following Bone Expansion. Open Journal of Stomatology, 7, 305-313.

https://doi.org/10.4236/ojst.2017.77025

Received: May 3, 2017

Accepted: July 14, 2017

Published: July 17, 2017

Copyright $\odot 2017$ by authors and Scientific Research Publishing Inc. This work is licensed under the Creative Commons Attribution International License (CC BY 4.0).

http://creativecommons.org/licenses/by/4.0/

c) (i) Open Access

\begin{abstract}
The placement of implants in edentulous areas is often compromised because of atrophic alveolar ridges. Several techniques have been suggested in the literature to increase inadequte bone width which includes bone grafting, distraction osteogenesis and bone expansion. Bone expansion technique is one of the most widely used methods which can also be utilized to increase the width of alveolar ridge and to provide sufficient bone volume for implant placement. The purpose of this study, is to measure the increase of the width of alveolar ridge after bone expansion following implant placement. Between 2013-2016, 30 consecutive, healthy, non-smoking, adult patients with atrophy of the maxilla and mandibula had 149 implants inserted. There were 18 women and 12 men, mean age 51.34 years (range 34 - 67). The initial width of the alveolar ridge measured from 2.5 to $3 \mathrm{~mm}$ (mean $2.83 \pm 0.2$ ) with Cone beam computed tomography ( $\mathrm{CBCT}$ ). The mean increase of bone width was achieved $1.25 \mathrm{~mm}$ (between $0.64 \mathrm{~mm}$ and $1.73 \mathrm{~mm}$ ). Before prosthetic rehabilitation, width of expanded alveolar bone was calculated from 3.50 to 4.75 $\mathrm{mm}$ with СBCT. During follow-up, 140 implants survived and 9 implants failed. The rate of implant survival was $93.95 \%$ after average 5 years follow-up. In conclusion, we suggest that, bone expansion is useful for managing the unsufficient ridges for implant placement.
\end{abstract}

\section{Keywords}

Inadequate Bone, Expansion, Dental Implant

\section{Introduction}

After tooth loss, histological and morphological changes of alveolar socket and adjacent soft tissue may undergo a series of tissue repair processes [1]. Implant treatment in alveolar ridge offers greater challanges of successful implant therapy depends on adequate bone quality and quantity [2]. However, inadequate 
amount of bone for implant placement at functionally and esthetically most appropriate position is a common problem. Placement of implants in atrophic ridges is often accompanied by various challenges [1] [3]. If inadequate bone exists, several surgical techniques may be used to reconstruct the deficient ridge for implant placement [4].

Investigators have adopted several techniques to remedy these consequences [5] [6], including guided bone regeneration (GBR) [7], onlay grafts [8], distraction osteogenesis [9], ridge expansion [10], and revascularized flaps [6]. The bone manipulation techniques are capable of manipulating the one's bones to alter their density to make them extremely durable and strong. These techniques mobilize vital bone with plastic bending, shaping, or condensation of tissue as a bone flap or bone-periosteal flap [11].

A multidimensional assessment of the available bone is the most important factor necessary for a sound treatment planning ensuring longevity and function of implant supported prosthesis. Determinants of available bone are: Height, Width, Length, Angle, Crown/implant ratio [12]. Cone beam Computerized tomography (CBCT) was introduced to the dental field to replace expensive and high-radiation-producing medical CT scans around twenty years ago [13].

We aimed to evaluate of bone width using CBCT in the pre-operatively assigned bone site for implant placement and bone around implants placed in the same designated site using drilling technique and bone expansion with splitting osteotomy postoperatively. It evaluates pre- and postoperative bone width around implants using CBCT scan in expanded bones.

\section{Material and Method}

\subsection{Patient Selection}

A clinical study was conducted on patients who reported during year 2013-2016 to the Department of Oral and Maxillofacial Surgery, Istanbul University. A total of 30 patients, mean age $=51.34$; range $=34-67$, female $=18$, male $=12$, with inadequate alveolar width were included in the study. Hygiene conscious, motivated and willing to participate and gave written informed consent and those having adequate vertical height were included in the study. Patients with severe atrophic ridges, those with co-existing vertical defect requiring additional corrective intervention, heavy tobacco users, systemic contraindications to surgery, including severe renal or liver disease, uncontrolled diabetics, insufficient bone height for placement of implants at least $10 \mathrm{~mm}$ long, and active periodontal disease involving the adjacent teeth immunocompromised patients and those who were poorly motivated and unable to keep the follow-up were excluded from the study. All patients were given an oral explanation and detailed informed consent form was signed by patient according to the Helsinki declaration).

\subsection{Measurement of Alveolar Bone Widt}

Patients who presented with partial or total edentulous space in maxilla and 
mandibula, having a ridge width of $2.5 \mathrm{~mm}$ to $6.0 \mathrm{~mm}$, measured pre- and postoperatively, using $\mathrm{CBCT}\left(\mathrm{PaX}-\mathrm{i} 3 \mathrm{D}^{\oplus}\right.$, VATech Global, Gyeonggi-do, Korea) (Figure 1, Figure 2).

\subsection{Surgical Procedures and Modified Splitting Osteotomy}

All surgical procedures were performed under aseptic conditions and following standard protocols. The baseline clinical examination consisted of a thorough medical and dental history, general and oral health status, assessment of future implant site. The available vertical, mesio-distal and labio-lingual bone dimension was determined by measurements from CBCT. The modified splitting osteotomy was done using osteotomes with mallets (Scwert ${ }^{\circ}$, Seitingen/ Oberflacht, Germany) and magic split (Magic Drill Kit ${ }^{\oplus}$, IBS Implant ${ }^{\oplus}$, Daejeon, Korea) (Figure 3). After maintained sufficient bone and the ridge was achieved, $3,3.5$ or $4 \mathrm{~mm}$ wide and 10 to $13 \mathrm{~mm}$ high implants were placed into the prepared site under local anesthesia (IBS Implant ${ }^{\oplus}$, Daejeon,Korea, Implant Direct $^{\oplus}$ Thousand Oaks, CA, USA) (Figure 4). After implamt placement, to

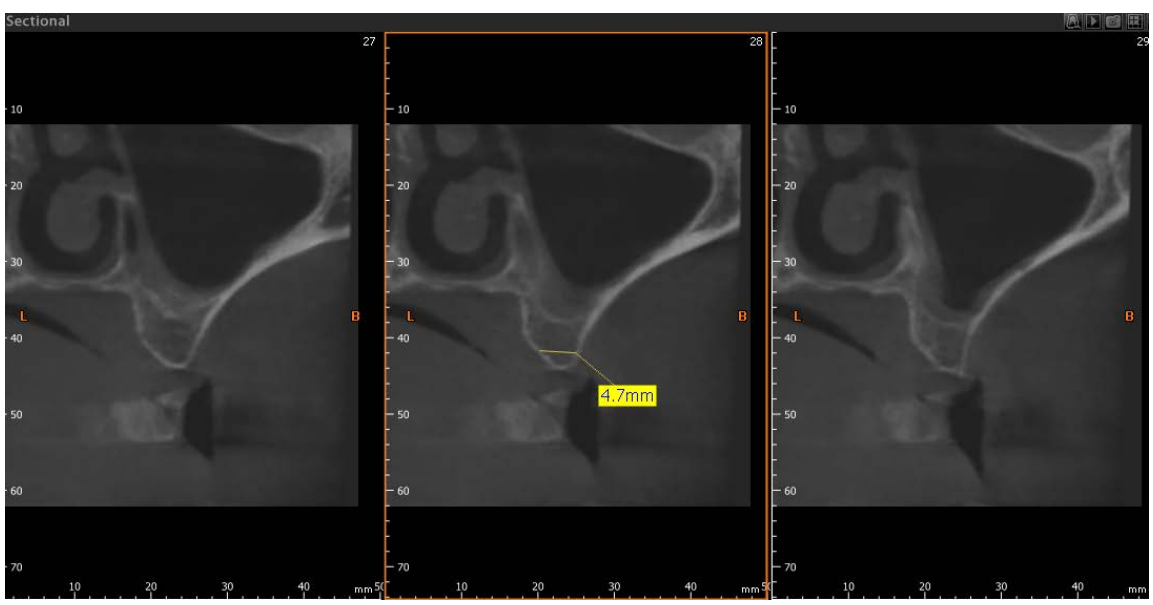

Figure 1. The measurement of alveolar ridge width on the cross-sectional CBCT image before the implant placement ( $62 \mathrm{y}$. female patient).

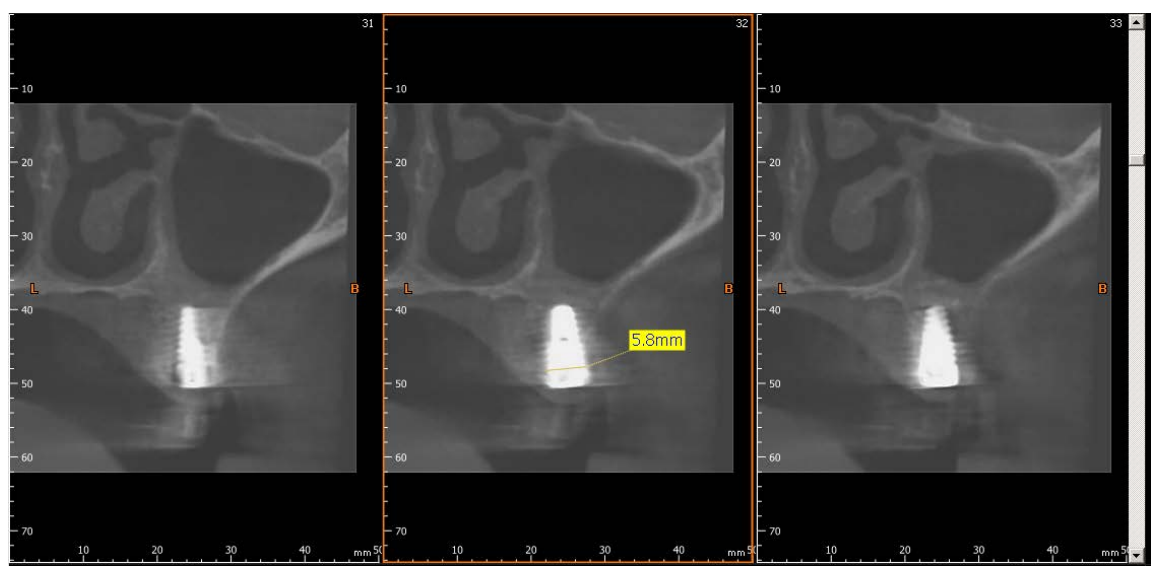

Figure 2. The measurement of alveolar ridge width on the cross-sectional CBCT image 8 months after the implant placement ( $62 \mathrm{y}$. female patient). 


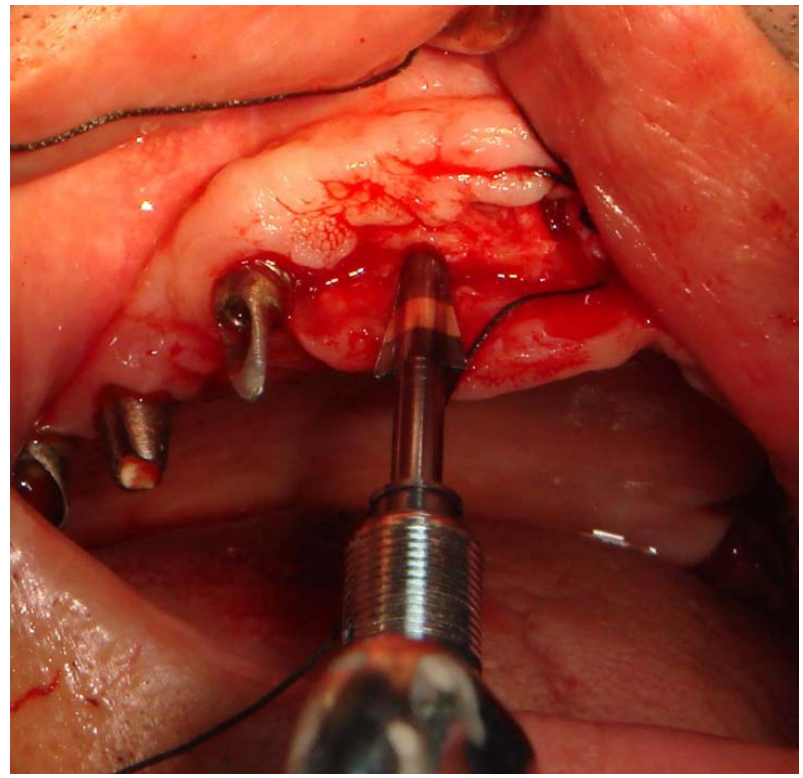

Figure 3. The preparation of the implant place with magic split ((Magic Drill Kit ${ }^{\oplus}$, IBS Implant system, Daejeon, Korea) (59 y. male patient).

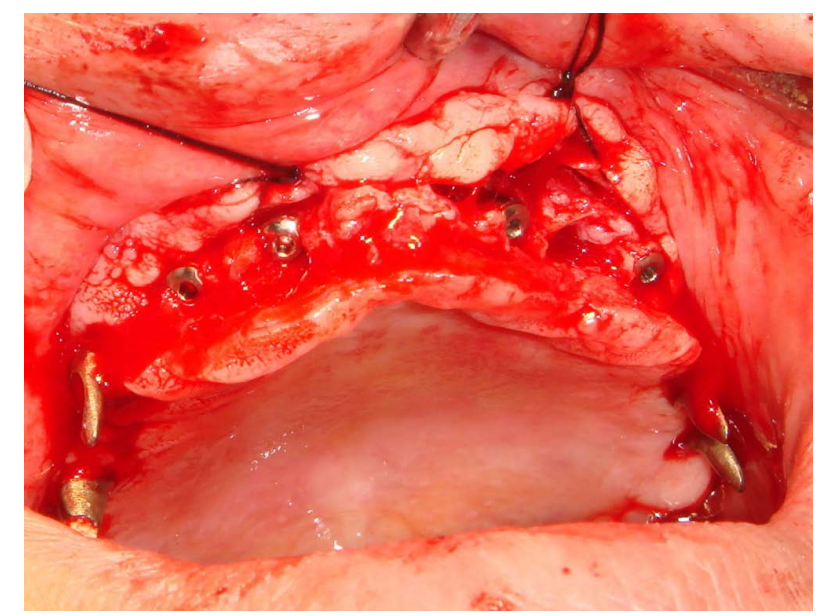

Figure 4. The placement of the implant after bone expansion (59 y. male patient).

increase bone density around the implants allografts (Corticocancelleus graft, Maxxeus ${ }^{\oplus}$ Dental, OH, USA) and membrane (Collagene $\mathrm{AT}^{\oplus}$, Centro di Odontoiatria Operativa S.r.l.,Padova,Italy) were placed for guided bone regeneration (Figure 5, Figure 6). The reflected mucoperiosteal flaps were re-approximated and sutured around implants with a sling suture to achieve a good seal, creating a tenting effect over the allograft and membrane sutured with using silk suture material (Figure 7). All implants were positioned by the same surgeon. All implants were placed on the same day as the bone was expanded. Sutures were removed 7 - 10 days postoperatively. All patients were given amoxicillin $1 \mathrm{~g}$ orally twice a day starting the day before operation and continuing for 5 days. Postoperative care consisted of rinsing with $0.2 \%$ chlor- 


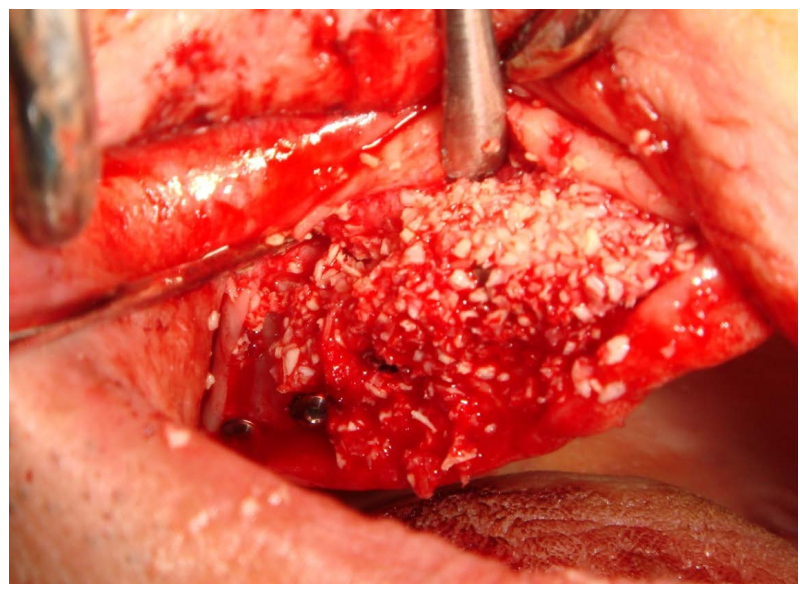

Figure 5. The placement of the allograft (Corticocancelleus graft, Maxxeus ${ }^{\circledast}$ Dental, OH, USA) (59 y. male patient).

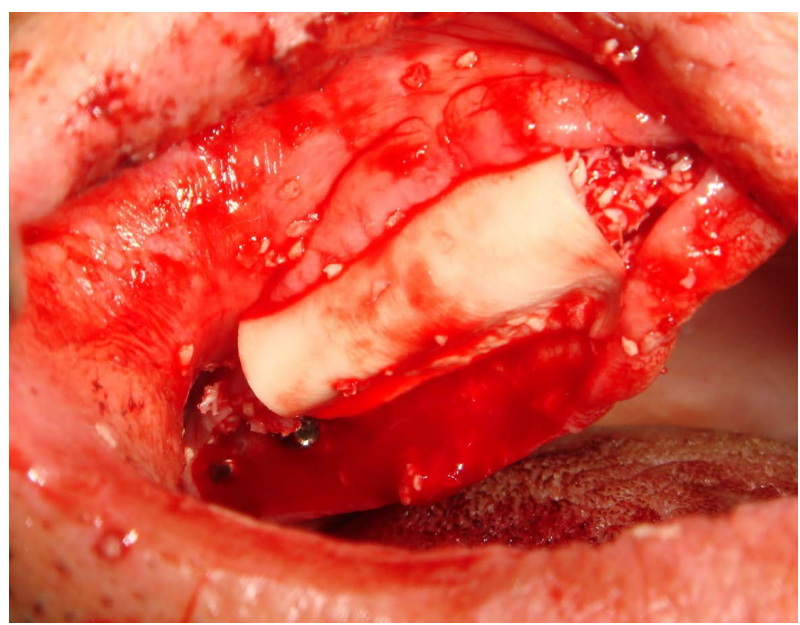

Figure 6. The placement of the membrane (Collagene $\mathrm{AT}^{\oplus}$, Centro di Odontoiatria Operativa S.r.l.,Padova, Italy) (59 y. male patient).

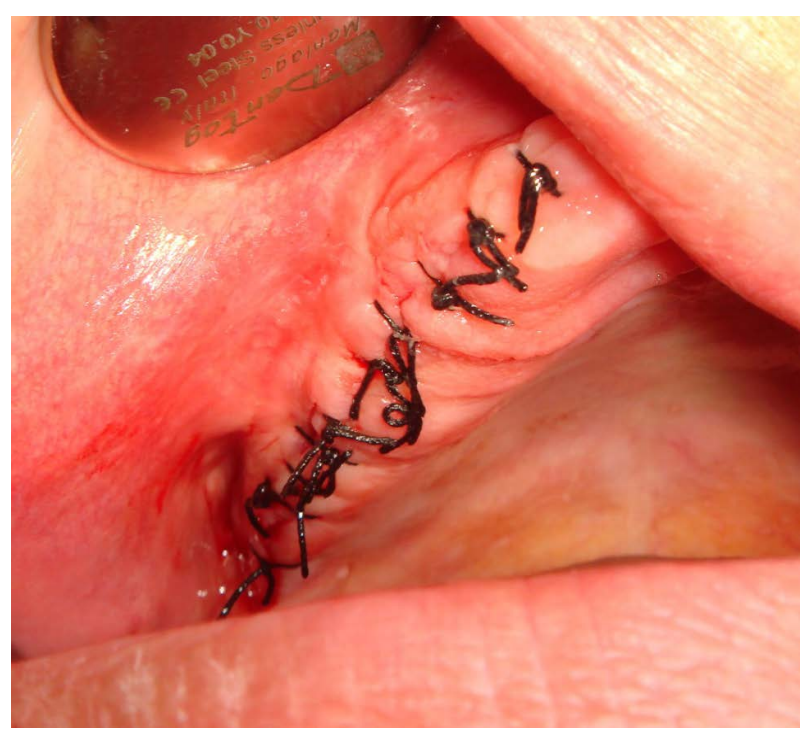

Figure 7. The primer on sutures for wound closure. 
hexidine twice daily for 10 days, and a soft diet. Non-steroidal analgesics were prescribed as needed for pain control. Three to four months after placement of the implants, abutments were connected and prosthetic rehabilitation begun. Before prosthetic rehabilitation, expanded bone width measurement was done with СВCT. Prosthetic rehabilitation was achieved for all patients (Figure 8) and followed-up during 5 years.

\section{Results}

Between 2013-2016, 30 consecutive, healthy, non-smoking, adult patients with atrophy of the alveolary bone had 149 implants (107 (71.81\%) were in maxilla, $42(28.19 \%)$ were in mandible) inserted. There were 18 women and 12 men, mean age 51.34 years (range $34-67$ ).

The initial width of the alveolar ridge measured from 2.5 to $5 \mathrm{~mm}$ (mean 2.83 \pm 0.2 ) with CBCT. The mean increase of bone width was achieved $1.25 \mathrm{~mm}$ (between $0.64 \mathrm{~mm}$ and $1.73 \mathrm{~mm}$ ). Before prosthetic rehabilitation, width of expanded alveolar bone was calculated from 3.50 to $5.95 \mathrm{~mm}$ with CBCT. During follow-up, 103 implants (96.26\%) were survived and 4 (3.74\%) implants were failed in maxilla. 37 implants $(88.09 \%)$ were survived and 5 implants (11.91\%) were failed in mandible. (Table 1). The total rate of implant survival was $93.95 \%$ after average 5 years follow-up. No infection was noted during the postoperative period and healing was uneventful.

\section{Discussion}

Bone expansion technique is defined as the manipulation of the bone to form a

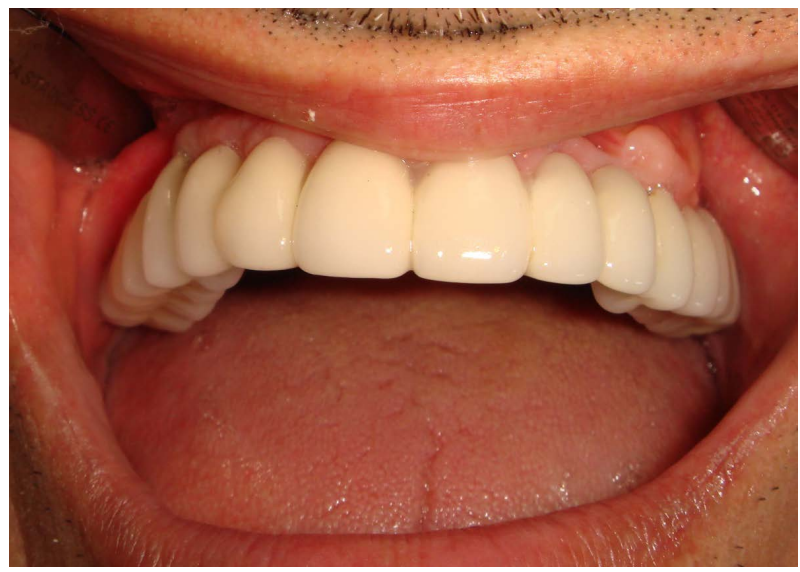

Figure 8. The prosthetic rehabilition.

Table 1. Distribution of inserted implants $(n=149)$.

\begin{tabular}{ccc}
\hline Situation of implants & Maxilla & Mandible \\
\hline Survived & $103(96.26 \%)$ & $37(88.09 \%)$ \\
Failed & $4(3.74 \%)$ & $5(11.91 \%)$ \\
Total & $107(71.81 \%)$ & $42(28.19 \%)$ \\
\hline
\end{tabular}


receptor site for an implant without the removal of any bone from the patient [14]. The objective is to maintain the existing soft bone by pushing the buccal bony plates of the residual ridge laterally with minimal trauma. This technique takes the advantage of the softer bone quality found in Types III and IV bone by relocating the alveolar bone rather than losing the precious bone by drilling [15]. In the present study we performed bone expansion with splitting osteotomy. Ridge expansions have been used to expand narrow alveolar ridges, however maxillary expansions were successful then mandibulary expansions. The purpose of this study was to evaluate the efficacy of ridge gain by ridge expansion.

These result in contour or dimensional changes, while preserving bone integrity and viability. The concept is to manipulate the residual bone to create an intrabony cavity with a wider base or taller roof that heals like an extraction site, with access of mesenchymal stem cells and the normal wound healing mechanisms. The morphology of bony defect is an important consideration in the selection of a method for ridge manipulation. The fewer the number of remaining bony walls, the greater is the need for osteopromotive techniques [4].

The minimum implant length an ideal bone density situation is $10 \mathrm{~mm}$. Allowing a margin of $2 \mathrm{~mm}$ from the vital landmarks such as inferior alveolar canal is recommended. Favorable width is defined as the distance between the buccal and the lingual plates, measured at the crest. Each $1 \mathrm{~mm}$ increase in diameter increases the surface area by about $20 \%-30 \%$, thus, increasing diameter effectively; decreases crestal stress. Therefore, implant diameter is much more critical than its length [4]. After bone expansion, 3, 3.5 or $4 \mathrm{~mm}$ wide and 10 to $13 \mathrm{~mm}$ high implants were placed into the prepared site in the present study.

In cases of advanced bone loss, there is insufficient bone width for rehabilitation with implants, and other alternatives for bone increase must be considered [16] [17] [18]. In some patients, the use of narrow implants can solve some cases, but when the bone width is $3 \mathrm{~mm}$ or less it is not feasible to contemplate the safe and stable installation of dental implants [19]. In the present study, because of efficacy of bone expansion, there was no used narrow implants.

The use of CBCT, which is more objective and reliable, for the assessment of the bone width of the patients requiring implant therapy was introduced [20], and this method has been in utilized several studies [21]. CBCT used before and after bone expansion measurement in the study. Implants that did not cause any problems during 5 months of osteointegration were considered successful and the bone density was not measured to the prosthetic rehabilitation regardless of the bone density.

The placement of implants in edentulous areas is often compromised because of atrophic alveolar ridges. Several techniques have been suggested in the literature to increase inadequte bone width which includes bone grafting, distraction osteogenesis and bone expansion. Bone expansion technique is one of the most used methods which can also be utilized to increase the width of 
alveolar ridge and to provide sufficient bone volume for implant placement. More noninvasive technique of ridge splitting and expansion can be carried out easily, without much trauma to the patient. In conclusion, we suggest that, bone expansion technique is useful for managing the unsufficient ridges for implant placement especially in maxilla.

\section{Fund}

The present work was supported by the Research Fund of Istanbul University. Project No. 2016-21405

\section{References}

[1] Reich, K.M., Huber, C.D., Lippnig, W.R., Ulm, C., Watzek, G. and Tangl, S. (2011) Atrophy of Residual Alveolar Ridge Following Tooth Loss in an Historical Population. Oral Diseases, 17, 33-44. https://doi.org/10.1111/j.1601-0825.2010.01699.x

[2] Friberg, B., Jemt, T. and Lekholm, U. (1991) Early Failures in 4,641 Consecutively Placed Branemark Dental İmplants. A Study from Stage I Surgery to the Connection of Completed Prosthesis. The International Journal of Oral \& Maxillofacial Implants, 6, 142-146.

[3] Summers, R.B. (1994) The Osteotomy Technique: Part-2-The Ridge Expansion Osteotomy (REO) Procedure. Compendium., 15, 422-436.

[4] Misch, C.E. (1993) Contemporary Implant Dentistry. 2nd Edition, Mosby, St. Louis, Missouri.

[5] Chiapasco, M, Zaniboni, M. and Boisco, M. (2006) Augmentation Procedures for the Rehabilitation of Deficient Edentulous Ridges with Oral İmplants. Clinical Oral Implants Research, 17, 136-159. https://doi.org/10.1111/j.1600-0501.2006.01357.x

[6] Taylor, G.I. (1982) Reconstruction of the Mandible with Free Composite İliac Bone Grafts. Annals of Plastic Surgery, 9, 361-376. https://doi.org/10.1097/00000637-198211000-00003

[7] Dahlin, C., Andersson, L. and Linde, A. (1991) Bone Augmentation at Fenestrated İmplants by an Osteopromotive Membrane Technique. A Controlled Clinical Study. Clinical Oral Implants Research, 2, 159-165. https://doi.org/10.1034/j.1600-0501.1991.020401.x

[8] Triplett, R.G. and Schow, S.R. (1996) Autologous Bone Grafts and Endosseous Implants: Complementary Techniques. The International Journal of Oral \& Maxillofacial Implants, 54, 486-494. https://doi.org/10.1016/s0278-2391(96)90126-3

[9] Ilizarov, G.A. (1989) The Tension-Stress Effect on the Genesis And Growth of Tissues: Part I. The Influence of Stability of Fixation and Soft Tissue Preservation. Clinical Orthopaedics and Related Research, 238, 249-281.

[10] Engelke, W.G., Diederichs, C.G., Jacobs, H.G. and Deckwer, I. (1997) Alveolar Reconstruction with Splitting Osteotomy and Microfixation of İmplants. The International Journal of Oral \& Maxillofacial Implants, 12, 310-318.

[11] Cullum, D. (2010) Advances in Bone Manipulation: Part 2. Osteomobilization for Horizontal and Vertical İmplant Site Development. SORMS, 18.5, 1-44.

[12] Mittal, Y., Jindal, G. and Garg, S. (2016) Bone Manipulation Procedures in Dental Implants. Indian Journal of Dentistry, 7, 86-94.

https://doi.org/10.4103/0975-962X.184650 
[13] De Vos, W., Casselman, J. and Swennen, G.R. (2009) Cone-Beam Computerized Tomography (CBCT) Imaging of the Oral and Maxillofacial Region: A Systematic Review of the Literature. International Journal of Oral \& Maxillofacial Surgery, 38, 609-625. https://doi.org/10.1016/j.ijom.2009.02.028

[14] Borgner, R.A., Kirkos, L.T., Gougaloff, R., Cullen, M.T. and Delk, P.L. (1999) Computerized Tomography Scan Interpretation of a Bone Expansion Technique. Journal of Oral Implantology, 25, 102-108.

[15] Siddiqui, A.A. and Sosovicka, M. (2006) Lateral Bone Condensing and Expansion for Placement of Endosseous Dental Implants: A New Technique. Journal of Oral Implantology, 32, 87-94. https://doi.org/10.1563/786.1

[16] Andersson, B., Odman, P., Widmark, G. and Waas, A. (1993) Anterior Tooth Replacement with Implants in Patients with a Narrow Alveolar Ridge Form. A Clinical Study Using Guided Tissue Regeneration. Clinical Oral Implants Research, 4, 90-98. https://doi.org/10.1034/j.1600-0501.1993.040205.x

[17] Bedrossian, E., Tawfilis, A. and Alijanian, A. (2000) Veneer Grafting: A Technique for Augmentation of the Resorbed Alveolus Prior to Implant Placement. A Clinical Report. The International Journal of Oral \& Maxillofacial Implants, 15, 853-858.

[18] Cordaro, L., Amadé, D.S. and Cordaro, M. (2002) Clinical Results of Alveolar Ridge Augmentation with Mandibular Block Bone Grafts in Partially Edentulous Patients Prior to Implant Placement. Clinical Oral Implants Research, 13, 103-111. https://doi.org/10.1034/j.1600-0501.2002.130113.x

[19] Enislidis, G., Wittwer, G. and Ewers, R. (2006) Preliminary Report on a Staged Ridge Splitting Technique for Implant Placement in the Mandible: A Technical Note. The International Journal of Oral \& Maxillofacial Implants, 21, 445-449.

[20] Schwarz, M.S., Rothman, S.L.G., Rhodes, M.L. and Chafetz, N. (1987) Computed Tomography: Part I. Preoperative Assesment of the Mandible for Endosseos Implant Surgery. The International Journal of Oral \& Maxillofacial Implants, 2, 137141.

[21] Beer, A., Gahleither, A., Holm, A., Tschabitscher, M. and Homolka, P. (2003) Correlation of Insertion Torques with Bone Mineral Density from Dental Quantative CT in the Madible. Clinical Oral Implants Research, 14, 616-620. https://doi.org/10.1034/j.1600-0501.2003.00932.x

\section{Submit or recommend next manuscript to SCIRP and we will provide best service for you:}

Accepting pre-submission inquiries through Email, Facebook, LinkedIn, Twitter, etc. A wide selection of journals (inclusive of 9 subjects, more than 200 journals) Providing 24-hour high-quality service User-friendly online submission system Fair and swift peer-review system Efficient typesetting and proofreading procedure Display of the result of downloads and visits, as well as the number of cited articles Maximum dissemination of your research work

Submit your manuscript at: http://papersubmission.scirp.org/

Or contact ojst@scirp.org 